\title{
Noninvasive prenatal testing in China: Future detection of rare genetic diseases?
}

\author{
Lin Mei ${ }^{1,2}$, Qi Tang ${ }^{1}$, Baiyu Sun ${ }^{2}$, Lingzhong $\mathrm{Xu}^{1, *}$ \\ 'Department of Health Care Management and Maternal and Child Health, Shandong University, Ji'nan, Shandong, China; \\ ${ }^{2}$ School of Stomatology, Shandong University, Ji'nan, Shandong, China.
}

\begin{abstract}
Summary Noninvasive prenatal testing (NIPT) provides an innovative method to detect genetic conditions in fetuses using a maternal blood sample, thus avoiding the risk of miscarriage associated with traditional invasive procedures. Since $80 \%$ of rare diseases are genetic diseases, NIPT has the potential to detect rare genetic diseases early on and it has been used in many countries and regions. Since China has the world's largest population of patients with rare diseases, NIPT has been implemented in China since 2010. However, the regulations governing NIPT in China are weak and NIPT oversight and research are still lacking. Strict registration is needed to ensure the quality of NIPT, additional certification can help a developer/manufacturer of an NIPT test to compile clinical data and to improve innovation, and academic societies can provide committee opinions that are suited to the current situation in China. These efforts may improve regulations governing NIPT and NIPT oversight and research in China. With these improvements, NIPT may offer promise in terms of the early detection of rare diseases.
\end{abstract}

Keywords: Premarket notification, Laboratory Developed Tests (LDTs), Clinical Laboratory Improvement Amendments (CLIA), Committee opinion

On February 12, 2014, Ariosa Diagnostics, Inc. obtained licensure approval from New York for Harmony ${ }^{\mathrm{TM}}$ noninvasive prenatal testing (NIPT) (1). This testing uses fetal genetic material obtained from a maternal blood sample to carry out genetic sequencing in order to detect certain genetic conditions during pregnancy based on the discovery of free fetal DNA in maternal plasma (2). NIPT offers advantages compared to traditional invasive procedures. NIPT can be performed with a maternal blood sample, which means that it is not associated with a risk of miscarriage. This aspect also means that NIPT is better suited to screening (3). Therefore, NIPT is likely to serve as a tool to screen for genetic defects in fetuses without risking a miscarriage.

Since $80 \%$ of rare diseases are genetic diseases (4), any method that can help to detect genetic conditions

\footnotetext{
*Address correspondence to:

Dr. Lingzhong Xu, Department of Health Care Management and Maternal and Child Health, NO.110 mailbox, Shandong University, 44 Wenhuaxi Road, 250012 Ji'nan, Shandong, P.R. China.

E-mail: lzxu@sdu.edu.cn
}

can be seen as a possible way to respond to rare diseases. Earlier diagnosis and treatment of diseases like phenylketonuria can mean a better prognosis (57). Therefore, prenatal testing is more likely to help improve the treatment of rare diseases than newborn testing, and this is especially true for rare diseases $(5,6,8)$. As mentioned earlier, NIPT avoids the risk of miscarriage associated with traditional invasive procedures, and this aspect means that NIPT is more likely to detect rare genetic diseases early on. Currently, NIPT is focused on detecting genetic diseases such as Trisomy 21, 18, and 13, Turner syndrome, 22q11.2 deletion syndrome, and 1 p36 deletion syndrome, all of which are rare genetic diseases.

China is a country with the world's largest population of patients with rare diseases (7), and China faces huge challenges in responding to rare diseases. Faced with these challenges, China has adopted several strategies to improve the healthcare of patients with rare diseases, including reimbursement of medical expenses for children with congenital heart disease and leukemia (9) and a new born screening program $(5,10)$. As NIPT has matured, this technology has been marketed 
$(11,12)$ (Table 1). NIPT has been implemented in China since May 2010, and most NIPT technology is from US companies (22). In China, NIPT can test for Trisomy 21, 18, and 13 just as NIPT in Europe can, but NIPT in the US can test for 4 more conditions (Turner syndrome, Triploidy detection, 22q 11.2 deletion syndrome, and 1 p36 deletion syndrome). China has the largest number of tested samples, approximately twice the number in the US and 33 times that in Europe, which shows that China has a large market for NIPT.

However, regulations governing NIPT in China are still weak and NIPT management is still lacking. Since the first NIPT was carried out in China in 2010, approximately 210,000 samples have been tested without oversight because of the lack of regulations. Under these circumstances, the China Food and Drug Administration (CFDA) and National Health and Family Planning Commission of the People's Republic of China (NHFPC) jointly issued a "Notice on the enhanced clinical use of products related to genetic sequencing and increased oversight of genetic sequencing" on February 9, 2014 (23). This move indicates that the Chinese government has begun overseeing the market for NIPT-related products. On March 3, 2014, the NHFPC issued a "Notice regarding approval procedures for a pilot project involving clinical use of high-throughput genetic sequencing" (24) to improve the system for registration of genetic sequencing in China. These notices are mainly focused on criteria and authority for registration. Regulations on how NIPT should be performed and maintaining its quality are still lacking.

The US government has experience overseeing NIPT that may be helpful: $i$ ) Strict registration is needed to ensure the quality of NIPT. In the US, a developer/ manufacturer of an NIPT test must first obtain a $510(\mathrm{k})$ premarket notification (510k) from the US Food and Drug Administration (FDA) (25). The 510k requires an in vitro diagnostic test yield a certain number of positive results from among tested samples. Using Trisomy 21 as an example, Trisomy 21 has an incidence of $1 / 1000$. Given a target of 100 positive results, at least 100,000 samples would have to be tested to meet the requirements of a $510 \mathrm{k}$. This requirement ensures the quality of any NIPT test approved for a $510 \mathrm{k}$. ii) Additional certification can help a test developer/ manufacturer to compile clinical data and to improve innovation. Since obtaining the number of positive results required by a $510 \mathrm{k}$ is difficult, only one NIPT device has been approved by the FDA. Applying for Laboratory Developed Tests (LDTs) certification and Clinical Laboratory Improvement Amendments (CLIA) certification from the Centers for Medicare \& Medicaid Services (CMS) (26) provide another way for a developer/manufacturer to certify an NIPT test without clinical data. LDTs and CLIA certification are focused more on the developer/manufacturer's knowledge, training and experience, reagents and materials

Table 1. Current state of NIPT in the United States, Europe, and China

\begin{tabular}{|c|c|c|c|c|c|c|}
\hline Region & Company & Service & Diseases tested for & Date started & $\begin{array}{l}\text { Number of } \\
\text { samples tested }\end{array}$ & Ref. \\
\hline \multirow[t]{4}{*}{ United States } & Sequenom & MaterniT21 ${ }^{\mathrm{TM}}$ PLUS & $\begin{array}{l}\text { Trisomy } 21 / \text { Trisomy } 18 \text { / Trisomy } \\
13 \text { / Turner syndrome/ } 22 \mathrm{q} 11.2 \\
\text { deletion syndrome/ } 1 \mathrm{p} 36 \text { deletion } \\
\text { syndrome }\end{array}$ & October 2011 & $\begin{array}{l}100,000 \\
\text { (as of April 16, } \\
2013 \text { ) }\end{array}$ & (13) \\
\hline & Natera & Panorama $^{\mathrm{TM}}$ & $\begin{array}{l}\text { Trisomy } 21 / \text { Trisomy } 18 / \text { Trisomy } \\
\text { 13/ Turner syndrome/ Triploidy } \\
\text { detection / } 22 \mathrm{q} 11.2 \text { deletion } \\
\text { syndrome/ } 1 \mathrm{p} 36 \text { deletion syndrome }\end{array}$ & Unknown & Unknown & (14) \\
\hline & Verifi & Verifi $^{(}$ & $\begin{array}{l}\text { Trisomy } 21 / \text { Trisomy } 18 / \text { Trisomy } \\
\text { 13/ Turner syndrome }\end{array}$ & March 2012 & Unknown & $(15,16)$ \\
\hline & Ariosa & Harmony Prenatal Test ${ }^{\mathrm{TM}}$ & $\begin{array}{l}\text { Trisomy } 21 / \text { Trisomy } 18 / \text { Trisomy } \\
\text { 13/ Turner syndrome }\end{array}$ & May 2012 & $\begin{array}{l}40,000 \\
\text { (as of November } \\
13,2013 \text { ) }\end{array}$ & (17) \\
\hline Europe & LifeCodexx & PrenaTest $^{\circledR}$ & Trisomy 21/ Trisomy 18/ Trisomy 13 & August 2012 & $\begin{array}{l}\text { Nearly } 6,000 \\
\text { (as of August } \\
22,2013 \text { ) }\end{array}$ & $(18,19)$ \\
\hline \multirow[t]{2}{*}{ China } & BGI & NIFTY & Trisomy 21/ Trisomy 18/ Trisomy 13 & May 2010 & $\begin{array}{l}109,582 \\
\text { (as of April 2, } \\
2013 \text { ) }\end{array}$ & $(12,20)$ \\
\hline & Berry genomics & BambniTest & Trisomy 21/ Trisomy 18/ Trisomy 13 & April 2011 & Over 100,000 & $(11,21)$ \\
\hline
\end{tabular}

NIPT: noninvasive prenatal testing 
preparation, characteristics of operational steps, calibration, quality control, and proficiency testing materials, test system troubleshooting and equipment maintenance, and interpretation and judgment (26). This certification can help a developer/manufacturer that does not have enough tested samples to market a NIPT test, and most manufacturers of NIPT tests in the US currently have their NIPT products certified based on LDTs and CLIA. After the developer/manufacturer obtains CLIA certification, the Centers for Medicare $\&$ Medicaid Services (CMS) will conduct subsequent inspections on a biennial basis or with such frequency as necessary to ensure compliance, thus requiring the developer/manufacturer to maintain the quality of its test (27). And study has also indicated that LDTs and CLIA certification can improve innovation (28).

Research into NIPT in China is still lacking. With a new technology like NIPT, recommendations or official opinions should be provided by academic societies to give guidance on how NIPT should be used and where the cutting edge of research lies. As of this writing, however, there are no such recommendations or opinions in China been reviewed. Several opinions on NIPT have been issued by academic committees in places like the U.S., Europe, Canada, and Japan from December 2012 to May 2013 (29,30). These opinions include statements on the clinical use of NIPT, the limitations of current NIPT, who is eligible to undergo NIPT, and guidelines for medical staff. In order to enhance research into NIPT in China, academic societies of geneticists, obstetricians, gynecologists and specialists in maternal-fetal medicine should provide committee opinions that are suited to the current situation in China.

NIPT has potential in terms of detecting rare genetic diseases and it has been used in many countries and regions. China is a country with the world's largest population of patients with rare diseases patients, and China has implemented NIPT since 2010. However, NIPT oversight and research in China are still lacking. With the improvement of these aspects, NIPT may offer promise in terms of the early detection of rare diseases.

\section{References}

1. Ariosa diagnostics. Ariosa Diagnostics Secures New York Lab Licensure Approval for the Harmony ${ }^{\mathrm{TM}}$ Prenatal Test. http://www.ariosadx.com/news-andevents/140212_Harmony_NY_approval.pdf (accessed May 19, 2014).

2. Lo YM, Corbetta N, Chamberlain PF, Rai V, Sargent IL, Redman CW, Wainscoat JS. Presence of fetal DNA in maternal plasma and serum. Lancet. 1997; 350:485-487.

3. Daley R, Hill M, Chitty LS. Non-invasive prenatal diagnosis: Progress and potential. Arch Dis Child Fetal Neonatal Ed. 2014. (Published Online First)

4. Batshaw ML, Groft SC, Krischer JP. Research into rare diseases of childhood. JAMA. 2014; 311:1729-1730.
5. Jones S, Hruban RH, Kamiyama M, et al. Exomic sequencing identifies PALB2 as a pancreatic cancer susceptibility gene. Science. 2009; 324:217.

6. Ng SB, Buckingham KJ, Lee C, Bigham AW, Tabor HK, Dent KM, Huff CD, Shannon PT, Jabs EW, Nickerson DA, Shendure J, Bamshad MJ. Exome sequencing identifies the cause of a mendelian disorder. Nat Genet. 2010; 42:30-35.

7. Wang JB, Guo JJ, Yang L, Zhang YD, Sun ZQ, Zhang YJ. Rare diseases and legislation in China. Lancet. 2010; 375:708-709.

8. Roberts NJ, Vogelstein JT, Parmigiani G, Kinzler KW, Vogelstein B, Velculescu VE. The predictive capacity of personal genome sequencing. Sci Transl Med. 2012; 4:133ra58.

9. Sarah LB, Lan Y. Health insurance systems in China: A briefing note. http://www.who.int/healthsystems/topics/ financing/healthreport/37ChinaB_YFINAL.pdf (accessed May 20, 2014).

10. Mei L, Song PP, Kokudo N, Xu LZ, Tang W. Current situation and prospects of newborn screening and treatment for Phenylketonuria in China - compared with the current situation in the United States, UK and Japan. Intractable Rare Dis Res. 2013; 2:106-114.

11. Berry Genomics. Berry Genomics and Xiangya Hospital of Central South University team up to offer "NIPT for Down's syndrome". http://www.berrygenomics.com/ news/detail.aspx?nid=125 (accessed May 20, 2014). (in Chinese)

12. BGI. The Wuhan Health Bureau holds a symposium to promote a pilot project involving NIPT in Wuhan. http:// www.genomics.cn/news/show_news? nid $=852$ (accessed May 20, 2014). (in Chinese)

13. Sequenom. Sequenom CMM achieves milestone of 100,000 MaterniT2 $1^{\mathrm{TM}}$ PLUS test processed. http:// www.sequenom.com/press/sequenom-cmm-achievesmilestone-100000-maternit21-plus-tests-processed (accessed May 20, 2014).

14. Natera. Compare your options. http://www.panoramatest. com/compare_options (accessed May 20, 2014).

15. Verifi. Clinical data. http://www.verifitest.com/clinicaldata/ (accessed May 20, 2014).

16. Verifi. verifi ${ }^{\circledR}$ prenatal test. http://www.verifitest.com/ healthcare-professionals/ (accessed May 20, 2014).

17. Ariosa Diagnostics. Ariosa Diagnostics Provides Harmony ${ }^{\mathrm{TM}}$ Prenatal Test to Over 40,000 Women and Expands into More than 50 Countries in the Third Quarter of 2013. http://www.ariosadx.com/news-andevents/131112-Harmony_leader_press_release.pdf (accessed May 20, 2014).

18. LifeCodexx. PrenaTest ${ }^{\circledR}$. http://lifecodexx.com/ lifecodexxprenatest-en.html (accessed May 26, 2014).

19. LifeCodexx. LifeCodexx performs close to 6,000 PrenaTest $^{\circledR}$ analyses in its first year. http://lifecodexx. com/6000prenatestinthefirstyear.html (accessed May 26, 2014).

20. iNFZM.com. Prenatal testing for women without a birth permit. http://www.infzm.com/content/89574 (accessed May 20, 2014). (in Chinese)

21. Berry Genomics. Why BambniTest?. http://www. berrygenomics.com/product/dzp.aspx? tid $=38$ (accessed May 20, 2014). (in Chinese)

22. Rare Diseases in China. Illumina does "PR work" in China as it seeks preliminary approval to initiate genetic sequencing. http://www.hanjianbing.org/content/ 
details 9 1702.html (accessed May 26, 2014). (in Chinese)

23. China Food and Drug Administration. Notice from the NHFPC regarding the enhanced clinical use of products related to genetic sequencing and increased oversight of genetic sequencing. http://www.sda.gov.cn/WS01/ CL0845/96853.html (accessed May 20, 2014). (in Chinese)

24. Henan Provincial Health Bureau. The Henan Provincial Health Bureau disseminates the NHFPC's notice regarding approval procedures for a pilot project involving clinical use of high-throughput genetic sequencing. http://www. henanyz.com/images/artpic/2014032155693709.pdf (accessed May 26, 2014). (in Chinese)

25. FDA. Premarket Notification (510k). http://www.fda. gov/medicaldevices/deviceregulationandguidance/ howtomarketyourdevice/premarketsubmissions/ premarketnotification $510 \mathrm{k} /$ default.htm\#who (accessed May 21, 2014).

26. American Academy of Family Physicians. CLIA Inspections. http://www.aafp.org/practice-management/ regulatory/clia/inspections.html (accessed May 22, 2014).

27. FDA. CLIA Categorizations. http://www.fda.gov/
MedicalDevices/DeviceRegulationandGuidance/ IVDRegulatoryAssistance/ucm 393229. htm (accessed May 22, 2014).

28. Ferreira-Gonzalez A, Emmadi R, Day SP, Klees RF, Leib JR, Lyon E, Nowak JA, Pratt VM, Williams MS, Klein RD. Revisiting oversight and regulation of molecularbased laboratory-developed tests: A position statement of the Association for Molecular Pathology. J Mol Diagn. 2014; 16:3-6.

29. American College of Obstetricians and Gynecologists Committee on Genetics and the Society for MaternalFetal Medicine Publications Committee. Committee opinion: Noninvasive prenatal testing for fetal aneuploidy. http://www.acog.org/ /media/Committee\%20Opinions/ Committee\%20on\%20Genetics/co545.pdf? dmc $=1 \&$ ts $=20$ 14011370806506426 (accessed May 21, 2014).

30. Devers PL, Cronister A, Ormond KE, Facio F, Brasington CK, Flodman P. Noninvasive prenatal testing/ noninvasive prenatal diagnosis: The position of the National Society of Genetic Counselors. J Genet Couns. 2013; 22:291-295.

(Received June 20, 2014; Revised July 26, 2014; Accepted August 1, 2014) 